\title{
Contra imagens: apagamento, iconoclastia, devoração e demonização
}

\begin{abstract}
Alberto Klein'
Resumo: Este artigo pretende tipificar gestos de insurgência contra as imagens, a saber: o apagamento, a iconoclastia, a devoração e a demonização. Eles constituem uma resposta a algo dito anteriormente pela imagem, sendo frutos de agenciamentos específicos. A identificação destas atitudes se evidencia a partir da interlocução de pesquisas entre Mondzain, Mitchell, Belting e Baitello Jr.
\end{abstract}

Palavras-chave: Imagem. Iconoclastia. Economia da Imagem. Demonização.

\section{Against images: erasure, iconoclasm, devouring and demonization}

\begin{abstract}
This article intends to typify gestures of insurgency against images, namely: erasure, iconoclasm, devouring and demonization. They constitute a response to something previously said by the image, and are the result of specific agencying. The identification of these attitudes is evidenced from the research interlocution between Mondzain, Mitchell, Belting and Baitello Jr.
\end{abstract}

Keywords: Image. Iconoclasm. Image Economy. Demonization.

I Doutor em Comunicação e Semiótica pela Pontifícia Universidade Católica de São Paulo. Professor do Programa de Mestrado em Comunicação da Universidade Estadual de Londrina. Entre os anos de 2019 e 2020 atuou como pesquisador convidado no Instituto de Mídia e Comunicação da Universidade de Hamburgo, Alemanha. Universidade Estadual de Londrina, PR 445, KM 380, CEP 86057-970. E-mail: klein@uel.br ORCID: https://orcid.org/0000-0002-5701-0328. Lattes iD: http://lattes.cnpq.br/3458784367523009. Londrina, PR, Brasil. 


\section{Agenciamentos e Economia da Imagem}

As querelas iconoclastas dos séculos VIII e IX, em Bizâncio, e do século XVI, por ocasião da Reforma Protestante, são reiteradamente convocadas em reflexões sobre a caracterização do gesto iconoclasta em oposição a uma atitude iconófila, ou, simplesmente, idólatra, para recuperar o termo acusatório dos iconoclastas.

De fato, estes dois eventos demarcam, por um lado, em seus respectivos contextos históricos, pontos de tensionamento comuns sobre a presença e legitimidade das imagens no seio das práticas cristãs. Por outro lado, a distância temporal de seis séculos entre eles faz emergir singularidades e circunscrições próprias a cada uma dessas experiências, referentes aos argumentos teológicos empregados de ambos os lados, a dimensão política e social que atravessa cada um deles, bem como a própria concepção que se tinha de imagem e o que ela encarnava.

Portanto, torna-se arriscado fazer considerações generalizantes de processos históricos radicalmente distintos, motivados por razões sociais, políticas e religiosas diferentes, ainda que se assemelhem por cenas que são comuns, a saber a violência dirigida contra a imagem. Uma forma de insurgência, mobilizada por afetos e que se expressava, em muitas ocasiões de um modo espetacular. Entretanto, os argumentos de Nicéforo (Mondzain, 2013), no contexto bizantino, ressoaram teologicamente na Igreja Católica Romana do século XVI e estava na linha de frente dos defensores da imagem com o intuito de condenar iconoclastas.

Ainda assim, uma recuperação histórica dos levantes contra imagem não pode prescindir da constatação de que, mesmo havendo demarcações históricas a serem consideradas, o gesto iconoclasta se apresenta numa intermitente linha temporal, em que suas eclosões se tornam cada vez mais comuns à medida que o mergulho da cultura ocidental se aprofunda no oceano das imagens midiáticas. Os gestos e afetos extrapolam a condição religiosa da imagem, abarcando múltiplas experiências, seja na arte, entretenimento, informação, nos modos de produção de identidades culturais, formas de expressão e identificações sociais e políticas, ou até mesmo na enunciação do self nas redes sociais. Em todas estas dimensões, além de outras possíveis, a imagem se coloca como um modo de convergência de comunicação e afetos. Ela não é apenas veículo, meio, canal de enunciação de sujeitos ou grupos, um instrumento utilizado segundo os desejos humanos, mas, inver- 
samente, projeta-se, inquire o olhar o observador, como se fosse dotada de vida própria, provocativa, estimulando sensações, despertando paixões, ou até mesmo indignação. Ou seja, a imagem nos olha de volta, para recuperar a proposta de Didi-Huberman (2010) em "O que vemos, o que nos olha".

Este retorno do olhar da imagem pode se verificar como incômodo, inadequado, imoral, afrontoso, conforme condições específicas de sua expressão no tempo e no espaço. A iconoclastia coloca-se, em tais casos, como uma resposta no horizonte. Contudo, há outros modos de se insurgir contra a presença da imagem e seu olhar provocativo. A ideia de insurgência aqui se mostra como um movimento reativo, confirmando modos de agenciamento distintos da imagem sobre um indivíduo ou uma coletividade.

O objetivo deste trabalho é tipificar ao menos quatro dessas formas insurgentes, a saber: 1) o apagamento, que pode também ser entendido como censura, resultando na retirada de circulação de imagens em razão de seu caráter imoral; 2) Iconoclastia, compreendida no seu sentido clássico como um gesto violento dirigido contra as imagens; 3) Devoração, consumo obsessivo de imagens midiáticas, reduzindo-as a superfícies sem sentido; e 4) Demonização, compreendida sob um duplo aspecto: a demonização das imagens do outro e a demonização do outro por imagens.

Tais forma anteveem um modo de agir primeiro da imagem. Parte-se do pressuposto de que a imagem é capaz de mobilizar afetos e despertar reações específicas. Os agenciamentos podem assim se bifurcar em repostas extremas, seja a iconofilia ou a iconoclastia, sem deixar de entrever gradações possíveis.

Mitchell (2005, p.125) se pergunta sobre a razão dessa suscetibilidade dos indivíduos ao poder das imagens. Afinal, por que as pessoas se ofendem diante de determinadas imagens e por que sua resposta é igualmente uma ofensa, expressa por um ato de vandalismo, muitas vezes teatralizado? A resposta do autor leva em consideração duas hipóteses. A primeira é de que em muitos casos as imagens não se desvinculam daquilo que representam (2005, p.127). Signo e referente se confundem, de maneira que a imagem, entendida como signo, leva a culpa por aquilo que está veiculando. A segunda é que há, em determinadas situações, uma concepção de que as imagens são organismos vivos, com intenções próprias, capazes de agenciamento. $E$, como um ser vivente, ela poderia semelhantemente ao ser humano, sentir dores ou sofrer (2005, p.127). "Imagens deste tipo parecem olhar-nos de 
volta, endereçar-nos sua fala, são até capazes de sentir dores ou expressar a dor quando a violência as acomete" (2005, p.127)1.

De fato, este tipo de mentalidade se coloca numa perspectiva atemporal e perpassa uma série de experiências da imagem em diversas culturas. Vincula-se à ancestralidade da emergência do duplo na linguagem e na cultura, conforme Morin.

\begin{abstract}
A linguagem já abriu a porta à magia: desde o momento em que toda a coisa chama imediatamente ao espírito a palavra que a designa, a palavra chama no mesmo instante a imagem mental que a coisa evoca, conferindo-lhe, mesmo que esteja ausente, a presença (s/d, p. 99)
\end{abstract}

A concepção do duplo implica conferir vida a imagens, coisas e palavras, dando contornos definitivos à experiência da magia e do rito. Segundo Morin, símbolos e imagens garantem, pelo rito, uma negociação com o mundo exterior. Tal negociação, entretanto, não se dá apenas por meio das imagens, mas com elas, uma vez que encarnam aquilo que representam. Neste sentido, não é adequado neste contexto discutir uma binaridade entre signo e objeto. Experimentar símbolos significa viver a sua epifania, para usar a expressão de Durand (2000).

As discussões em torno do caráter mobilizador da imagem, sua capacidade de agenciamento, de nos inquirir e instigar afetos, em geral, ignora um conceito norteador, que se inscreve na cultura cristã medieval como uma doutrina, com alto grau de racionalização, justamente em meio às querelas iconoclastas. Mondzain (2013) demonstra como a noção de economia tornou-se operatória na transição de uma fé, em que a presença da imagem era recusada, ou vista com desconfiança, para uma religião em que o ícone se coloca como um ponto nevrálgico da experiência do sagrado. Num horizonte ampliado, não seria incorreto dizer que a doutrina econômica da imagem desempenha um papel central ao autorizar o surgimento de uma cultura visual no ocidente cristão.

1 Trecho original: "Images of this sort seem to look back at us, to speak to us, even to be capable of suffering harm or of magically transmitting harm when violence is done to them". 
Se oikonomia, originalmente, tal como postulado por Aristóteles (2011), designa a gestão dos recursos da casa, Mondzain vai se concentrar nos desdobramentos conceituais deste vocábulo em aplicações diversas pelos pais da igreja nos primeiros séculos, mas especialmente Nicéforo, teólogo em Bizâncio, que deu a ele demarcações definitivas. Nas palavras de Modzain, foi num período de crise que o conceito adquiriu sua sistematicidade (2013, p.20). Em seu cerne, o termo se refere a um modo de Deus se mostrar aos homens, por meio da encarnação, a fim de realizar seu plano. Economia regeria, neste sentido, as relações entre o sagrado, a natureza e a razão. Das aplicações possíveis encontradas na patrística, economia pode ser traduzida como plano, encarnação, administração (Mondzain, 2013, p. 31). Tem interfaces com a retórica, uma vez que designa um modo de apresentação do divino. A economia especula também os efeitos desses modos de se expressar.

Pois a economia é, inicialmente, a arte de Deus para convencer e salvar os homens. Por ser a economia uma arte, e por não haver arte isenta de artifício e que não resulte de um pensamento mimético, aquele que é mestre nela nos convida a imitá-lo. A retórica é um efeito secundário da economia, não o inverso (2013, p.31)

Há um emprego polissêmico de economia. Se num certo aspecto, economia pode ser enunciada como um conceito que equilibra as relações entre o visível e o invisível na manifestação do sagrado, por outro lado se liga também à gestão dos afetos desta manifestação. Trata-se de uma arte de Deus para convencer o homem. "O ouvido e o olho não passam de canais, de orifícios que abrem o corpo visceral para o discurso. O discurso e a imagem devem falar com as entranhas" (2013, p.85). Neste aspecto, negar o mistério do ícone seria recusar todo arcabouço da economia. Mais que isso, contestar um artifício divino. Estão aí teologicamente justificadas as astúcias da imagem, nos limites da experiência religiosa, que instiga, envolve, fala ao homem, como princípio de uma elocução viva de Deus. Esta ideia esteve na base da consolidação da imagem como objeto da prática iconófila no Segundo Concílio de Niceia que, num de seus artigos, argumentava: "a honra da imagem se dirigia ao original" (1963, p.112).

O grande problema da astúcia da imagem, suas insinuações ao corpo e à mente, seu poder de sedução, é que ela pode advir do Diabo. Basta simplesmente trocar os polos. Assim, a linha entre o divino e o diabólico são imprecisas se observarmos o fenômeno do agenciamento imagético apenas pelos seus efeitos. 
A imagem levantará os mesmos problemas de negociação de nossa fraqueza no caminho que conduz à salvação. Não se contentará em lembrar e instruir, mas será preciso que emocione. À visão dela, os olhos enevoados de lágrimas serão iluminados por uma evidência proveniente do coração. Como escreveu Grumel, "não se pode privar a Igreja de uma arma tão poderosa para combater o demônio". Às vezes, é preciso combatê-lo com suas próprias armas. Assim, a oikonomia torna-se sublimação do diabólico, uma vez que a serviço do bem colocam-se forças que são desviadas da ameaça e da captação infernais (Mondzain, 2013, p.86).

A articulação do conceito de economia, vista de fora de uma perspectiva teológica, ajuda a compreender como uma doutrina, sistematizada principalmente na Igreja do Oriente, sacramentou a cultura da imagem no Ocidente. Permite também identificar a constituição subjacente de uma teoria da imagem que ultrapassava seu caráter sígnico e mergulhava nos mistérios de sua experiência, sob a ótica da revelação divina. Se extrairmos as bases místicas que sustentam este conceito, obviamente ele se desfaz. Mas forneceria pistas interessantes para pensar os modos de agenciamento da imagem na contemporaneidade. Até porque não se pode subtrair da discussão sobre os modos de agenciamento da imagem sua retórica, suas dissimulações no objeto representado, suas estratégias de inquirir e sondar os nossos órgãos sensoriais, sua capacidade de mexer com nossas vísceras. Obviamente, subjaz a todos estes processos, uma questão de fundo, também eminentemente econômica, que é a gestão de sua visibilidade.

A tríade proposta por Belting (2006), imagem - corpo - mídia, no escopo da elaboração de sua antropologia da imagem, fornece ocasião para pensarmos tal relação a partir de uma perspectiva econômica. Embora não especule diretamente sobre os modos da imagem se projetar sobre o corpo, instigando afetos e mobilizando reações intensas, o autor compreende imbricações pouco usuais entre estas três instâncias, que deixam brechas para analisar agenciamentos pelas imagens.

Em primeiro lugar, antevê a imagem a partir de sua dupla natureza, endógena e exógena. O primeiro lugar de habitação das imagens é o próprio corpo. Em segundo lugar, é considerar a mídia, como um aparato análogo ao corpo - não apenas como extensão, conforme propunha McLuhan (1979) -, uma espécie de corpo simbólico, bem como o dispositivo que torna visível a imagem. Tais vínculos são claramente econômicos, na medida em que lidam com a gestão do trânsito da imagem entre corpo e mídia, bem como com a administração de sua presença ou visibilidade, seja no corpo ou no meio. Por exemplo, imagem e mídia constituem uma espécie de amálgama, mesmo 
se constituindo ontologicamente de coisas distintas. Trata-se ao cabo de se indagar o quê, que remete à imagem, ou como, que inquire o meio. É a mídia que garante visibilidade à imagem e trata de animá-la. Imagens dependem essencialmente de sua medialidade dada por um aparato. Nesta relação, ora o meio reivindica a primeira voz, ou seja, questões sobre as formas de mediação se sobrepõe ao conteúdo, ora a imagem se destaca, garantindo uma presença vívida, conforme Belting (2006). Neste sentido, esta modulação entre imagem e meio é decisiva para elucidar, sob os aspectos econômicos, as duas condições propostas por Mitchell acerca do agenciamento que as imagens exercem sobre os indivíduos, a saber: a indistinção entre a imagem e o que ela representa, bem como sua projeção como um ente animado, vivo, capaz de sofrer. Estes dois fatores pressupõem economicamente o modo como as imagens reivindicam esta primeira voz, deixando em segundo plano as questões mediacionais, permitindo um impacto maior sobre a percepção. Belting não explora as dimensões do afeto, mas é certo que os agenciamentos da imagem depreendem-se desta adequação triádica.

A natureza endógena da imagem, por sua vez, independe das suas circunscrições midiáticas. É o próprio corpo que se coloca como lugar/mídia das imagens. Para fins de explorar do gesto iconoclasta, isto traz uma consequência decisiva, pois seu objetivo se volta para retirar as imagens de circulação. Seu drama é poder eliminar apenas sua medialidade física. Inversamente, as imagens endógenas podem se fortalecer simbolicamente mesmo na ausência de seus suportes.

Repensar o agenciamento sob o encaminhamento da economia da imagem, conforme foi desenvolvida por Mondzain, é fundamental para caracterizarmos os gestos de insurgência que se projetam sobre as imagens. Assim, proponho quatro atitudes em que a imagem é objeto de ofensa, violência ou censura. São elas: o apagamento, a iconoclastia, a devoração e a demonização.

\section{Apagamento}

No filme "Brilho eterno de uma mente sem lembranças" (Michel Gondry, EUA, 2004), um casal se submete a um procedimento de extração de memórias, com o objetivo de apagar totalmente suas experiências amorosas que haviam se convertido em desilusões. A eliminação de vestígios de uma presença sempre se colocou no horizonte de debates acerca do caráter ofensivo das imagens. 
O que se busca, como nota Belting (2006) acima, é tirar as imagens de seu circuito. Entretanto, este varrer de memórias ou dos sinais que restaram da presença constitui-se como uma operação mais complexa do que uma intervenção diretamente no cérebro, como mostra o filme.

O desejo de apagamento da imagem defronta-se com a condição de nos situarmos em uma cultura centrada na visualidade, em que todas as coisas cedem ao apelo da visibilidade midiática no consumo cotidiano de informações. Neste sentido, as operações de apagamento, sejam elas operacionalizadas por uma censura prévia ou posterior, evocam tensões e confrontações, conforme o interesse público, que acabam gerando ainda mais visibilidade em torno do objeto de disputa. Outro desafio que praticamente inviabiliza o apagamento total de uma imagem é o fato de o espaço digital, que abarca quase a totalidade das experiências comunicacionais, se apresentar como um gigantesco banco de dados, de caráter cumulativo, que permite a reatualização de uma memória de maneira instantânea se o usuário assim o desejar. Estes dois aspectos impedem que o sonho do iconoclasta se cumpra na sua totalidade: viver em um espaço livre de imagens ou, especificamente, daquelas imagens que o ofendem. Elas retornam sempre pela porta dos fundos.

Uma questão de base, tomando-se a perspectiva do iconoclasta, é, diante da impossibilidade do apagamento total, dado o contorno midiático da cultura, como administrar a visibilidade da imagem. Este modo de gestão, conforme os princípios da economia, poderiam orientar o grau de visibilidade da imagem, a intensidade dos afetos mobilizados por ela, bem como a sua tematização no espaço público. De todo modo, aquele que deseja retirar a imagem de seu circuito raramente o faz em silêncio se a sua presença for ultrajante.

Muitos desses casos possuem um enquadramento político. Contudo, os mais eloquentes lidam com imagens que tematizam o sagrado por mais que ele apresente interfaces com a política. A seguir relaciono três exemplos de tentativas de apagamento da imagem, que resultaram em controvérsias públicas projetando, a contragosto dos censores, visibilidade ainda maior.

1. Em 1989, com o enredo "Ratos e urubus, larguem minha fantasia", a escola de samba Beija-Flor teve um carro alegórico censurado. Um cristo representado como mendigo seria exibido no desfile, mas foi censurado pela justiça a pedido da Arquidiocese do Rio de Janeiro. A solução encontrada pelo carnavalesco Joãozinho Trinta foi cobri-lo com sacos pretos de lixo, envolto em uma faixa com 
os dizeres: "Mesmo proibido, olhai por nós". A imagem coberta converteu-se no tema mais debatido daquele carnaval.

2. Em 1999, o artista plástico britânico Chris Ofili apresentou sua obra, Madonna, na amostra Sensations do museu do Brooklyn, em Nova York. Tratava-se de uma efígie de Maria, feita com estrume de elefante. Isto despertou a ira de católicos mais piedosos bem como do prefeito da época, Rudolph Giuliani. Houve várias tentativas de censura e ameaças de corte de financiamento público do museu. Um visitante lançou tinta branca sobre o quadro, num gesto tipicamente iconoclasta. Trata-se de um caso curioso, pois a ofensa foi proporcionada não pelo conteúdo da imagem, mas pelo material utilizado para sua confecção.

3. Em 2017, a exposição "Queer museu: cartografias da diferença na arte brasileira”, promovida pelo banco Santander, em Porto Alegre, provocou reação virulenta de grupos conservadores, como o MBL (Movimento Brasil Livre), que defendeu o encerramento da exposição e boicote ao banco. Uma das imagens, objeto de controvérsia, era uma pintura de Fernando Baril, intitulada "Cruzando Jesus Cristo com Deusa Shiva", representando Jesus com vários braços amputados em torno de sua imagem. O banco acabou cedendo à pressão de grupos conservadores e fechou a exposição.

Estes três casos geraram um acalorado debate nos meios de comunicação tradicionais bem como nas redes sociais. A irradiação do poder da imagem, mesmo que a tentativa de apagamento seja celebrada, torna-se ainda mais intensa em razão do debate público suscitado. Apagamento pressupõe sobretudo censura, não necessariamente destruição. Implica o exercício frio de uma razão que interdita, diante da imoralidade materializada pela imagem.

\section{Iconoclastia}

Diferentemente do apagamento, que se ampara pela censura, instrumentalizada, via de regra, pelo sistema de leis, a iconoclastia é um gesto violento que se volta contra as imagens com o intuito de destruí-la. Caracteriza-se por transbordar o exercício frio da racionalidade, resultando quase sempre em uma atitude desmedida. Marretas, fogueiras, dilacerações são métodos de destruição que conferem teatralidade a esses tipos de cena de destruição. Mesmo que o objetivo seja, por fim, o apagamento, o ato do iconoclasta quase sempre se reveste de espetacularidade. Por isso, o ato iconoclasta é geralmente perpetrado por alguém acometido pela fúria. Mitchell caracteriza a intensidade desta resposta disruptiva diante do caráter ofensivo das imagens.

As forças psicológicas que tornam as pessoas suscetíveis à ofensa de uma imagem são invisíveis e imprevisíveis. Mas quando elas se dispõem a ofender uma imagem, cen- 
surá-la, denunciá-la, ou puni-la, seu comportamento se dá em lugares que podemos ver. Um excesso teatral nos ritos de esmagamento, queima, mutilação, cobrir com tinta branca, lançar ovos ou excrementos, converte a punição das imagens em uma imagem espetacular em seu próprio direito (2013, p.126). ${ }^{2}$

Esta ponderação de Mitchell ressalta dois aspectos muito pertinentes para discussão.

Primeiramente, a capacidade de agenciamento que certas imagens possuem. Sua presença é tão ultrajante que acaba provocando reações virulentas e imprevisíveis. Agenciam emoções intensas ou, para usar expressões comuns à discussão sobre economia da imagem, revolvem as paixões e atingem as vísceras. Esta visceralidade está presente no acinte que a imagem constitui. Ela presentifica uma imoralidade por si só. Mas também se mostra no conjunto de emoções daquele que empunha uma marreta. Aqui, torna-se evidente que os agenciamentos produzidos pela presença ofensiva da imagem em um iconoclasta resultam em ações mais eloquentes, espetaculares e sonoras do que a de um devoto diante de um ícone religioso. Seu gesto também mira o sofrimento da imagem. Ainda que o iconoclasta teime em dizer de que se tratam de meras representações, há uma espécie de double-bind (Bateson, 1972) que rege sua racionalidade: por um lado, a imagem é considerada signo, veículo, forma de representação, por outro, está profundamente identificada com o que ela representa, a ponto de confundir com o objeto. Ela se torna uma espécie de epifania demoníaca. E é precisamente por essa condição que ela é vítima de excessos. Belting (1994) refere-se aos excessos praticados em determinados cantões calvinistas nos períodos mais quentes da Reforma:

\footnotetext{
Para além da simples remoção das imagens, ao invés de deixá-las onde estavam, deu-se um passo além, ao destruir suas faces e suas mãos, privando-as das características que mais impressionavam as pessoas. Se as imagens permitissem que tal sacrilégio seguisse impune, então ficaria comprovada claramente sua falta de poder. Caçoar das imagens era às vezes mais importante do que sua remoção (1994, p.461). ${ }^{3}$
}

2 Trecho original: The psychological forces that lead people to be offended by an image are invisible and unpredictable. But when people set out to offend an image, to censor, denounce, or punish it, their behavior is out in the open where we can look at it. A kind of theatrical excesso in the rituals of smashing, burning, mutilating, whitewashing, egg - and excrement - throwing turns the punishment of images into a spetacular image in its own right.

3 Versão em inglês: Beyond simply removing the images, a further step was to leave them where They were but to break off their faces and hands, thus depriving them of the features with which They had most impressed the people. If the image left this sacrilege unpunished, their powerlessness was all the more clearly proved. The 
Em segundo lugar, a violência da iconoclastia precisa lidar com outra contradição, conforme já pontuei em outro artigo (Klein, 2009). A espetacularidade do gesto é por si mesma uma imagem. Mais do que isso, uma imagem que deve ser, segundo as intenções do iconoclasta, amplamente irradiada. Fazem parte desse conjunto de gestos a derrubada das torres gêmeas, em 2001, e, no mesmo ano, a explosão das estátuas dos budas no Afeganistão pelo Talibã. Em ambos os casos, a intenção era gerar a maior repercussão possível. Imputa-se castigo às imagens pelo que elas representam. A questão fundamentalmente econômica trazida por Belting é que a destruição de seu suporte não acarreta a destruição da imagem. Simbolicamente, as torres gêmeas assimilaram um poder que, quando ainda em pé, não possuíam. Soma-se a esta possibilidade ainda o fato de que são os próprios iconoclastas que reiteram, legitimam e justificam o poder da imagem. E por conta deste poder que se sentem impelidos a responder. Registrar toda a cena, tornar midiaticamente visível seu gesto, imortaliza o objeto destruído, além de abrir um looping de constante rememoração de imagens em efígie.

Um último aspecto a ser considerado é a inadequação do gesto iconoclasta com os ambientes digitais. Para a fúria iconoclasta é necessário presença. Exige-se a materialidade do objeto a ser destruído. No horizonte dos gestos iconoclastas, a imaterialidade das imagens digitais não se acomoda bem. $\mathrm{O}$ desejo iconoclasta é latente, eclode de tempos em tempos, com a potência exigida pelas circunscrições culturais e históricas. Se a fúria e a espetacularidade dos gestos são pontuadas no espaço-tempo, o estado de latência pode ser representado por uma mão abaixada, de posse de uma marreta, que um dia se erguerá, pois não faltam imagens que a desafiam. A iconoclastia, desse modo, é garantia de que haverá uma reserva de imagens materiais que não sucumbirão à digitalização. Para o censor, não importa que as imagens sejam digitais ou físicas. Já, para um iconoclasta, é imprescindível que elas ocupem o espaço e sirvam ao show de sua própria destruição.

\section{Devoração}

Pode haver questionamentos quanto ao emprego da ideia de devoração como uma espécie de insurgência diante da imagem. De modo geral, ela não

mocking of images was sometimes more importante than their removal. 
se afina com a intensidade dos demais gestos que proponho. Nem mesmo compreende a presença da imagem como algo ofensivo. Entretanto, é possível identificar a devoração como uma resposta, ainda que seja um hábito central na cultura midiática contemporânea, ao excesso informacional e ao caráter invasivo das imagens.

A ideia de devoração extraio do conceito de iconofagia, desenvolvido por Baitello Jr. (2014). O autor parte de um diagnóstico segundo o qual a oferta excessiva de imagens no ambiente da mídia afeta profundamente seus modos de apropriação pelo corpo, colocando a experiência do olhar subitamente em uma crise. Isso se verifica principalmente pela inversão do vetor homem - imagem. A integração da imagem à lógica do consumo resulta, com a produção excessiva, na captura do olhar pela imagem. O movimento é da imagem, não do olho. Eis um modo de agenciar o corpo, buscando no esgotamento de sua superfície, alcançar, minimamente entre uma miríade de imagens concorrentes, visibilidade e, no máximo, persuasão.

Os cenários descritos por Baitello Jr são de esgotamento de experiências como observação e contemplação quando se vislumbra o estatuto da visão, mas também compreende uma crise da imagem, de esvaziamento de sentido em razão de sua inscrição numa torrente de informações visuais. O autor assim considera a devoração como a chave explicativa desse vínculo. As imagens que insidiosamente se lançam ao olhar, cercam-no para devorá-lo, em sua ânsia por visibilidade. Semelhantemente é pela devoração incessante de imagens pelos indivíduos que se responde a este cerceamento.

A iconofagia pode assim se caracterizar como uma patologia, um desequilíbrio na relação entre os indivíduos e as imagens. Esse vetor invertido que se traduz na sondagem do olhar pela imagem, mostra, por um lado, a incapacidade desta em ser sentida, apropriada. É como se a retina se tornasse refratária à imagem. Baitello Jr, neste sentido, recupera o pensamento de Kamper (2016), segundo o qual há um padecimento evidente dos olhos no ambiente midiático, mais do que isso, do próprio corpo, que não resiste à sua midiatização. A refração do olho e a devoração obsessiva me leva a considerar dois aspectos, que se traduzem como uma vingança do corpo à invasividade das imagens midiáticas.

O primeiro é a anestesia. O corpo deixa de sentir. Diante da aceleração súbita das coisas e da onipresença da imagem tem sua aisthesis debilitada (Rosa, 
2019; Virilio, 1993). Não sentir a imagem. Presenteá-la apenas com piscadelas, como se passássemos em alta velocidade por um outdoor, significa, minimamente, a recusa à fruição e a perda do sentido e, no limite, implica não vê-la, deixá-la na zona do invisível. Neste sentido, a crise de visibilidade, descrita por Kamper (2016), é uma crise da própria imagem; a virulência converte-se, ao final, num suicídio da própria imagem.

Em segundo lugar, a ideia de devoração pode ser encarada como uma estratégia de sobrevivência do indivíduo diante da onipresença da imagem. Afinal, era como forma de sobrevivência e resistência ao colonialismo que Oswald de Andrade enxergava a antropofagia. A iconofagia é devoração, segundo Baitello; não um lento mastigar, deglutir e digerir. Entre os modos de lidar com a oferta excessiva de imagem, restam-nos poucas alternativas senão anestesiar a língua e a garganta para incorporar o intenso fluxo de informações cotidianas. Assim, a devoração reitera a perda de densidade e volume das imagens. Precisam ser achatadas, esvaziadas e simplificadas para que caibam na boca. Baitello Jr (2007) vincula a devoração à escalada da abstração de Flusser, que representa a evolução dos códigos comunicacionais no sentido de uma desmaterialização do mundo. Fica evidente que a devoração, aqui encarada como uma espécie de vingança contra a própria imagem, acentua-se diante de sua virulência nos espaços imateriais do universo digital. A digitalização do mundo transfigura tudo em imagem. Só com muita gula pode-se caminhar por esses espaços.

\section{Demonização}

O mecanismo de demonização por meio de imagens é um fenômeno que eclode com frequência em contextos de polarizações culturais, seja no âmbito da política, religião ou outras manifestações sociais, em que a demarcação de limites representacionais precisos dá ensejo a uma nítida separação entre "nós" e "eles". Nele se evidencia uma forma de operar a divisão entre santos e pecadores, civilização e barbárie, conhecimento e ignorância, luz e trevas. Além disso, estabelece o lugar de existência do Outro, delimitando as condições sob as quais este pode aparecer e ser representado nos meios de comunicação. Gilbert Durand (2000) afirma que a representação é uma forma de controle sobre o outro, ou sobre o que se desconhece.

Há uma série de investigações, no campo da mídia e da literatura que exploram essas condições de visibilidade da alteridade. Vale destacar o trabalho 
de Edward Said (2007), que cunhou a expressão "Orientalismo", a fim de demonstrar como a representação do árabe foi determinada historicamente pelo discurso do colonizador, a ponto de se constatar que o Oriente Médio, ou o oriental, é puramente uma invenção ocidental.

As imagens, além de se colocarem como a expressão preferencial na mídia contemporânea para assinalar o lugar do Outro, assumem também uma função projetiva com o objetivo de desfigurá-lo, desconstruí-lo, associando-o ao grotesco, cumprindo simbolicamente os anseios de destruí-lo, uma vez que a demonização justifica qualquer forma de eliminação, seja ela simbólica ou física. Aí reside o fenômeno que ora denominamos como imagem demonizada. Ele implica, por um lado, o esvaziamento simbólico do Outro na sua complexidade existencial, fixando nele elementos simbólicos daquilo que a cultura instituída nega. A demonização é operada a partir de estereótipos e imagens que transitam nas zonas de sentido do grotesco. Por outro lado, há uma tentativa atribuir ao Outro uma característica ameaçadora. Em tais delimitações, ele deve expressar não apenas valores diametralmente opostos a esfera da cultural de quem o demoniza, mas também intimidar, assombrar. Daí a preferência por elementos grotescos neste tipo de operação.

A demonização pode ocorrer de duas maneiras: a) a demonização do outro por imagens; e b) a demonização das imagens do outro. No primeiro caso, não se trata de forma alguma de uma atitude que se volta contra a imagem. Pelo contrário, serve-se dela para figurar o inimigo. Exemplos deste modo de representação são abundantes em contextos de polarização política, com farta produção visual em diferentes linguagens, como a charge, ou memes em redes sociais, com conteúdos emoldurados pelo humor. Da mesma maneira, usa-se muito deste expediente no fotojornalismo ou nas fotomontagens em veículos tradicionais da imprensa. No segundo caso, são os símbolos do outro que são ressignificados. Neste processo de demonização, a imagem encarna não somente uma série de valores que deve ser rechaçada, mas é geralmente atravessada pela sensação de risco, ameaça, ou simplesmente, um perigo que deve ser afastado a todo custo. Exemplo muito eloquente deste modo de demonização está no mote "nossa bandeira jamais será vermelha", que circula entre grupos conservadores no Brasil. Muito comum observar em redes sociais imagens que representam ideias de esquerda serem constantemente ofendidas, com xingamentos ou palavras de ordem, como se fossem entes vivos. Do ponto de vista econômico, pouco se distingue entre a imagem e o que ela representa. Em geral, esse processo desemboca em ritos iconoclastas, como queima de bandeiras ou imagens do gênero. 
Bystrina (1989) aponta que um dos padrões de solução para assimetrias do negativo, no campo da semiótica, é a eliminação. Por isso, é previsível que as imagens demonizadas sejam muitas vezes vítimas de uma verdadeira ritualização iconoclasta. A demonização, portanto, funciona quase sempre como uma antessala da iconoclastia.

\section{Considerações Finais}

A iconoclastia vem classicamente sendo tratada como uma das formas mais destacáveis de se insurgir contra as imagens. De fato, os debates em torno dos movimentos iconoclastas, tanto em Bizâncio quanto no período da Reforma, ajudaram a pautar muito das questões atuais acerca de tensões atuais envolvendo a imagem (Latour, Weibel 2002; Machado, 2001). Contudo, o gesto iconoclasta deve ser considerado em uma moldura mais ampla que contempla outros modos de se insurgir.

Por isso proponho quatro modos que demonstram, seja em uma perspectiva histórica ou conjuntural, ante a presença incômoda da imagem, gestos de insurgência, a saber: o apagamento (censura), a iconoclastia, a devoração e a demonização. Não considero tais procedimentos definitivos, afinal os agenciamentos provocados pela imagem e a indisposição do comportamento humano podem gerar estratégias distintas de insurgência, até o mesmo o silêncio.

Neste trabalho, procurei expor como o conceito de economia da imagem, muito debatido na Patrística, pode ainda operacionalizar reflexões sobre o poder de agenciamento das imagens, guardando obviamente as diferenças de contextos históricos que nos separam. Se há, entretanto, possibilidades de pontes a serem construídas, isto é um sinal de que tanto o poder exercido pelas imagens, seja de repulsa ou fascínio, quanto as respostas a ele não se limitam ao espaço-tempo.

\section{Referências}

ARISTÓTELES. Econômicos. São Paulo: Martins Fontes, 2011.

BAITELLO JR, Norval. A era da iconofagia: reflexões sobre imagem, comunicação, mídia e cultura. São Paulo: Paulus, 2014. 
BAITELLO JR, Norval. Flussers Völlerei. Köln: Buchhandlung Walther König, 2007.

BATESON, Gregory. Steps to an Ecology of Mind: Collected Essays in Anthropology, Psychiatry, Evolution, and Epistemology. [S.I.]: University Of Chicago Press, 1972.

BELTING, Hans. Likeness and presence: a history of the image before the era of art. Chicago: The University of Chicago Press, 1994.

BELTING, Hans. Pour une anthropologie des images. Paris: Gallimard, 2004.

BYSTRINA, Ivan. Semiotik der kultur: Zeichen - Texte - Codes. Tübingen: Stauffenburg, 1989.

DENZINGER, Enrique. El magisterio de la Iglesia. Barcelona: Herder, 1963.

DIDI-HUBERMAN, Georges. O que vemos, o que nos olha. São Pulo: Ed. 34, 2010.

DURAND, Gilbert. A imaginação simbólica. Lisboa: Edições 70, 2000.

KAMPER, Dietmar. Mudança de horizonte: o sol novo a cada dia. São Paulo: Paulus, 2016.

KLEIN, Alberto. Destruindo imagens: configurações midiáticas do iconoclasmo. In: E-Compós, V.12, n.2. Brasília, 2009.

LATOUR, B.; WEIBEL, P. Iconoclash. Cambridge: MIT Press, 2002.

MACHADO, Arlindo. O quarto iconoclasmo e outros ensaios hereges. Rio de Janeiro: Contra Capa, 2001.

MCLUHAN, Marshall. Os meios de comunicação como extensões do homem. São Paulo: Cultrix, 1979.

MITCHELL, W.J.T. What do pictures want: the lives and loves of images. Chicago: The University of Chicago Press, 2005.

MONDZAIN, Marie-José. Imagem, ícone, economia: as fontes bizantinas do 
imaginário contemporâneo. Rio de Janeiro: Contraponto, 2013.

MORIN, Edgar. O paradigma perdido: a natureza humana. Lisboa: Europa-América, s/d.

ROSA, Harmut. Aceleração: a transformação das estruturas temporais na modernidade. São Paulo: Ed. UNESP, 2019.

SAID, Edward. Orientalismo: o Oriente como invenção do Ocidentei. São Paulo: Cia das Letras, 2007.

VIRILIO, Paul. O espaço crítico. São Paulo: Ed. 34, 2014. 